\title{
Production Functions in Identifying the Specifics of Producing Gross Regional Product of Russian Federation
}

Tatiana Skufina ${ }^{1}$

Sergey Baranov 1

Vera Samarina ${ }^{2}$

Taisiya Shatalova ${ }^{1}$

1/nstitute of Economic Problems of the Kola Science Centre of the Russian Academy of Sciences

Apatity, Murmansk region Russian Federation

2Stary Oskol Technological Institute, branch of National Research Technological University "MISIS"

Stary Oskol, Belgorod region Russian Federation; Email: skufina@gmail.com

Doi:10.5901/mjss.2015.v6n5s3p265

\section{Abstract}

The paper presents the results of research about specifics of gross domestic product production in Russia using the tool of econometrics - production functions apparatus. Also, there are quantitatively found answers on questions, which have theoretical and methodological significance. First question - what has a decisive influencing on the production of gross domestic product in Russia, whether it is stocks or investments into the main fund? It was found that the decisive influence on the production of gross domestic product in Russia comes from investments into the main fund. Weak dependency of gross domestic product in Russia on capital stocks explains the inappropriateness of using capital stocks as a parameter of fund in production functions. Second question - what is the exact type of indicators that is preferred to use for characterizing the components of production function in conditions of the Russian economy - cost or natural? It is defined that is it possible to use both - cost terms indicators and indexes of physical volume. However, mining specifics of Russian economy defines the preference of using indexes of physical volume. Third question - what is the quality of economic growth of Russian economy during the period between 1996 and 2013? The intensive character of economic growth was found and the input of main factors of production into economic growth of Russian economy was measured.

Keywords: Russian economy, gross domestic product, production functions, modeling.

\section{Introduction}

Significance of econometric study regarding production of gross domestic product (GDP) of a country is defined exactly by this method's ability to find out objective and quantitative characteristics of the process of creating goods and services, define the specifics, tendencies, analytically built the optimal trajectory of economic development, and predict the future. Econometric study of production of GDP is associated with using system of indicators that are calculated as a relationship between results and factors of production (resources) or in another interpretation - results and costs associated with their achievement (Baranov, 2013; Chiang and Wainwright 2004, p. 318-333; Kurosawa 1975, p.157-159 and Shaikh, 1974)

\section{Literature Review}

Basic methodological approach to the statistical research of GDP production is production functions. Note, during the last years in the field of science there has been a distorted view about production functions. Quite often it is considered that production functions are easy and inadequate instrument for description of the processes of social production from the point of view of the up to date representations of modern systems, synergistic effects, that components of the model do not account for the new factors of production of information based society, and do not correspond to the potential of statistical base (Colacchio and Erratum, 2003). That is why the authors of publications dedicated to production functions often include a separate section «about applicability of power production functions for analysis in macroeconomics» (Baranov, 2013, p. 11-12 and Kirilyuk, 2013, p.294), introduce modifications that adopt production functions for the existing statistical base of Russia (Baranov, 2013, p.14-15 and Baranov and Skufina, 2007, p. 57-59). 
At the same time, fundamental and practical modern significance of production functions should not cause any doubts. Two sufficient evidences prove this. First, the tool of production functions is represented in every textbook of any recognized university in the world devoted to macroeconomics as whole, as well as to fundamental methods of mathematical economics (Chiang and Wainwright, 2004 and Mankiw 1977). Second, economic development of the world economy forecast forecast of IMF «World Economic Outlook» (2015), UN «World Economic Situation and Prospects» (2015) etc., of separate regions and countries (Epstein and Macchiarelli (2010); Hauptmeier et al. (2009), Ministry of Economy, Trade and Industry, (2011) are created by using production functions. Thus, modern tool of global and macroeconomic forecasts demonstrate that the base for those forecasts is the model of aggregate production functions. It is important to summarize that despite the criticism of using production functions as a tool for analysis and forecast, it is still widely used for the development of long-term forecasts of economic growth. We believe that value of production functions in macroeconomic research is explained by its simplicity (on practice with real data simple models tent to work very well) and unambiguous interpretation of calculated results in accordance with fundamental rules and established regularities (Baranov, 2013, p. 11-13; Blaug, 1962, p. 95-98, 408-419 and Kolemaev, 2002, p.14-26). As for the formal development forecast of the Russian economy, unfortunately, its methodical base in not published. Therefore, it is impossible to not only analyze the methodology and the results of the modeling of production of gross regional product but also it is unknown whether or not production functions are used in Russian forecasts. Moreover, scientific and practical significance of looking at specifics of production of Russia's GDP as based on proven statistical tools does not cause any doubts.

\section{Objectives, Methodology and Research Design}

The main goal of this paper is revealing the specifics of production of Russia's GDP by using apparatus of production functions.

Stages of the research are presented for justification of the answers on the questions.

1. What has a decisive influencing on the production of gross domestic product in Russia- stocks or investments into the main fund?

2. What indicators are preferable to use to characterize the components of production functions in condition of Russian economy - cost or natural?

3. What was the quality of economic growth in Russia between 1996 and 2013? Answers to the above questions have theoretical and methodical significance.

Ultimately generated answers on the above questions will help to reveal the features of GDP and quantitatively measure the contribution of the main factors of production into economic growth of the Russian economy.

Now we analyze the model and methodology of the study. Typically, modeling of macroeconomic processes is done based on the classical production functions. This is evidenced by the models presented in textbooks, specialized studies devoted to consideration of methodological tools of formal long-term forecast, results of the analysis using models of production functions for the Russian economy, publications of foreign researchers (Baranov and Skufina, 2007; Chiang and Wainwright K., 2004, p.311-342; Creel and Poilon, 2008; Kirilyuk, 2013 and McAdam and Willman A., 2013).

For modeling GDP production depending on the values of labour and capital we used Cobb-Douglas production function. Exactly such functions like Cobb-Douglas, formal properties of which are generalized to argument the fundamental statements, which are important for understanding the specifics of GDP.

First of all, marginal product of any factor varies only when there is a change in quantitates of used factors. Second of all, these factors have complementarity, which is; an increase in the number of variable factors reduces its marginal productivity, but increases the marginal productivity of fixed production factor. Third, total product is exactly the sum of the payments used as production factor in accordance with its marginal productivity.

In terms of formal properties, function like Cobb-Douglas connects the volume of production with the factors of production (capital and labour):

$Y(t)=A^{*} K(t)^{p *} L(t)^{q}$,

where $t$ - year; $Y$ - output; $K$ - capital; $L$-labour; $A$ - technological coefficient; $p$ - elasticity of capital; $q$ elasticity of labour. Estimated parameters $A, p, q$ are positive and $p+q=1$.

Reminder: coefficient of elasticity shows by how many percents the output is going to change if there is an increase in the factor by $1 \%$. Equal amount of elastic unit (100\%) allows determining the contribution of labour and capital into production output.

If $p>q$ there is labour-saving (intensive) growth, otherwise - fund-saving (extensive growth).

In the research model (1) the output is GDP, labour - average quantity of employed in the economy. For the capital 
values were used the costs of main capital funds adjusted for depreciation and investments into fixed capital. That is, modeling was made using both, the cost of main stocks in terms of capital and investments into fixed capital. Such approach helps to define what influences more the production of GDP, the cost of capital stocks (in fact it is the capital of the past invested and modified into assets that make up means of labour) or investments into the fixed capital (in fact it is production fund created in present).

Modeling was performed with both cost parameters and indexes of physical volume. Note, the use of indexes of physical volume allows to diminish the influence of outside factors on GDP, such as energy prices. Parameter estimation of Cobb-Douglas production function was performed by using the method of least squares after linearization of the expression (1). As a measure of model fit with the gained results there was used the corrected coefficient of determination:

$$
r^{2}=1-\frac{\sum_{t}\left(Y(t)-Y_{h}(t)\right)^{2}}{\sum_{t}(Y(t)-E[Y])^{2}},
$$

where $Y$ - actual value of output, $Y_{h}$ - output values obtained by the model, $E[Y]$ - average value of the actual output.

The determination coefficient is ranged from 0 to 1 . The closer is the value of the coefficient to $1(100 \%)$, the better is the fit of the gained results. The coefficient of determination shows the percentage variation of the initial data described by the model. Models with the coefficient of higher than $80 \%$ are considered to be good enough. Using estimated values of the parameters of Cobb-Douglas production function (1), the coefficient of efficiency of the economy depending on time was calculated:

$$
E(t)=\left[Y^{\prime}(t) / K^{\prime}(t)\right]^{p}\left[Y^{\prime}(t) / L^{\prime}(t)\right]^{1-p},
$$

where $\mathrm{t}$ - year, $Y, K, L^{\prime}-$ output, capital and labour, normalized to the corresponding value in the referenced $t_{0}: Y^{\prime}(t)=Y(t) / Y\left(t_{0}\right) ; K^{\prime}(t)=K(t) / L\left(t_{0}\right) ; L^{\prime}(t)=L(t) / L\left(t_{0}\right)$. For the cost indicators $t_{0}=2008$, but for indexed $-t_{0}=1995$ (no need for normalization while calculating). The calculations used data of the official statistics of Russia for the period between 1996 and 2013. Separately was calculated the index of the average quantity of employed in the economy. All of the indexes were leaded to values of 1995. All of the costs parameters are given in the year of 2008 pricing.

\section{Discussion of the Research Outcomes}

The results of modeling of GDP production in Russia is shown in Fig. 1, parameters of the model can be found in table 1. Analysis of the outcomes allows outlining the following facts.

First, it is noticeable that there is an absence of GDP dependence on the main capital stocks. This holds true for both, the case of using cost indicators (coefficient determinant of $r^{2}=0.09$ ) and the case of using the indexes of physical volume (coefficient of determination of $r^{2}=0.56$ ). Therefore, during statistical study of social production using production functions as capital, it makes sense to consider the dependence of GDP only on the investments into the main fund, see Fig. 1c, d.

Second, there is a clear dependence of GDP production on investments into the main fund. This statement is true for both models, when using the cost indicators $\left(r^{2}=0.96\right)$ and when using indexes of physical volume $\left(r^{2}=0.98\right)$.

Third, the value of elasticity of capital $(p)$ is greater than elasticity on labour $(q)$, thus, for the period from 1996 to 2013 there was labor-saving (intensive) growth. 

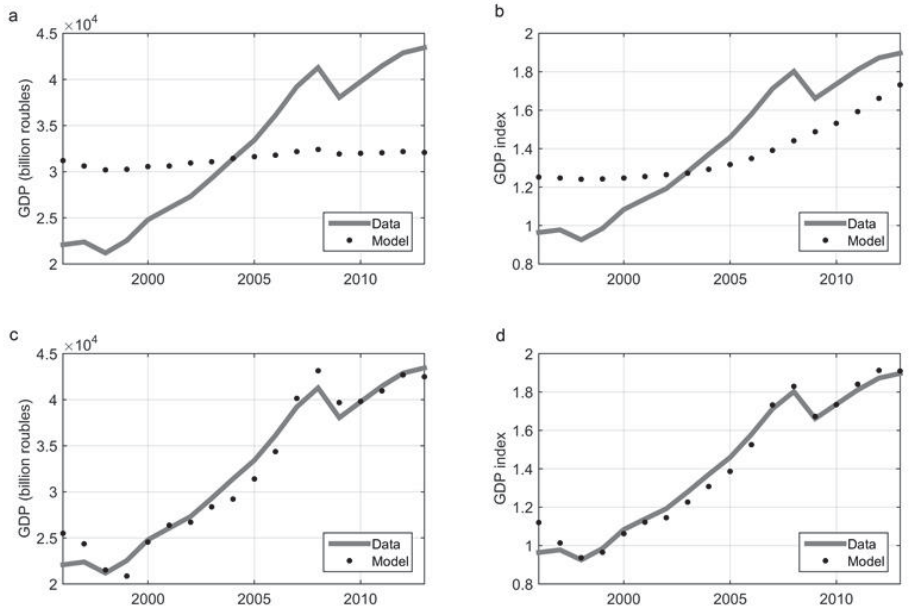

Figure 1 - (a) Modeling GDP in billion roubles with cost of main funds, adjusted for depreciation, as a capital; (b) Modeling index of physical volume of GDP with cost of main funds, adjusted for depreciation, as a capital; (c) Modeling GDP in billion roubles with Investments into the main fund as a capital; (d) Modeling index of physical volume of GDP with Investments into the main fund as a capital

Table 1 - Parameters of the model (1) when using as capital the cost of the main funds, adjusted for depreciation, and investments into the main capital for indicators, expressed in the cost and indexed units

\begin{tabular}{|lcccc|}
\hline Capital & $r^{2}$ & $p$ & $q$ & $A$ \\
\hline Models with cost values of indicators & & & & \\
Cost of main funds, adjusted for depreciation & 0.09 & 0.00 & 1.00 & 0.47 \\
Investments into the main fund & 0.96 & 0.68 & 0.32 & 2.57 \\
Models with index of physical volume & & & & \\
Cost of capital funds, corrected for depreciation & 0.56 & 1.00 & 0.00 & 1.26 \\
Investments into the main fund & 0.98 & 0.57 & 0.43 & 1.19 \\
\hline
\end{tabular}

Since the Cobb-Douglas (1) production function when using the cost of main funds as capital neither do not correspond to the real data, nor this correspondence is much worse than when using investments into the main fund, we will consider only the model with investments into the main fund.

Parameters of production function of Cobb-Douglas (1) for cost indicators and indexes of physical volume are close. When using cost indicators, the input into the production of GDP from the investment is $68 \%$, but the quantity of employed $-32 \%$. When using indexes of physical volume, the input into the production of GDP investments is $57 \%$, but the quantity of employed $-43 \%$. Somewhat big input of capital (accordingly, less labour input) when using in the model of cost indicators is explained by the influence of nonproduction factors, such as, world energy prices. Also, the changes in influence of outside factors do not cause any quality impact on the production of GDP (intensive character of growth is maintained).

We will now consider the effectiveness of Russian economy during the period between 1996 and 2013 calculated in the formula (2) using cost indicators (Fig. 2a) and indexes of physical volume (Fig. 2b). The qualitative behavior of effective economy, calculated by cost indicators and indexes of physical volume is same (growth corresponds to growth, decline to decline). Fluctuations in efficiency, calculated by using indexes of physical volume is less than when using the cost indicators. This is because, in the first case was excluded the influence of the outside factors on the GDP production. 

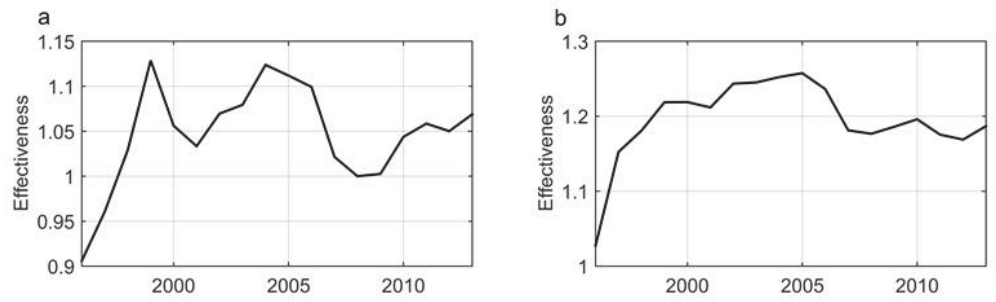

Figure 2 - The effectiveness of the Russian economy, 1996-2013, calculated based on the formula (2), using cost indicators (a) and indexes of physical volume (b)

Thus, it is possible to highlight the forth fact of the specification of GDP production in Russia, concerning the effectiveness of the economy.

Forth, the most rapid growth of the effectiveness of the economy (1.2 times) was observed during the period from 1996 to 1999. This statement holds true when we use cost indicators, or indexes of physical volume. In 2005, the effectiveness of production of physical volume of GDP in Russian Federation reached its maximum value. It was followed by decline and slight fluctuations around the average value.

\section{Conclusion}

To conclude, we should note the most important moments. When using models of production functions in the analysis and forecast of macroeconomic processes in Russia as a parameter of capital it is appropriate to use investments into the main fund and not the cost of the main funds. Methodological recommendation is based on slight dependency of production of GDP in Russia on the cost of main funds. From a management perspective this fact indicates the lack of effectiveness of forming and using main funds.

The results of modeling indicate, that it is possible to use both, cost value indexes and indexes of physical volume. However, the specifics of the export-oriented economy of Russia determines the preference of using indexes of physical volume, often eliminating the problem of outside factors that influence the production of GDP. During the period between 1996 and 2013 character of the economic growth in Russia was intense. In 2005 there was a maximum increase in the efficiency of the economy followed by stability. Revealed peculiarities of GDP support the conclusions that one of the perspective directions for regulating macroeconomic processes is increase in the effectiveness of creating and using main funds.

\section{Acknowledgement}

The study was supported by grants of RFBR №13-06-00030, RHF №14-02-00128, RHF №15-02-00127.

\section{References}

Baranov, S.V. (2013). Production functions: history, properties, problems and possibilities of usage in regional research. The economic analysis: theory and practice, 47, 11-15.

Baranov, S.V., \& Skufina, T.P. (2007). Modeling the production of gross domestic product in regions of Russian and nonnorthern part of Russian Federation. Statistical Issues, 2, 57-62.

Blaug, M. (1962). Economic theory in retrospect (1st ed.). Cambridge New York: Cambridge University Press.

Chiang, A.C. \& Wainwright K. (2004). Fundamental Methods of Mathematical Economics. McGraw-Hill/Irwin .

Colacchio, G. \& Erratum A. (2003). On the aggregate production function and its presence in modern macroeconomics. Structural Change and Economic Dynamics, 14 (1), 75-107.

Creel, J. \& Poilon G. (2008). Is public capital productive in Europe? International Review of Applied Economics, 22 (6), 673-691.

Epstein, N.P. \& Macchiarelli C. (2010). Estimating Poland's Potential Output: A Production Function Approach. IMF Working Papers, 120.

Hauptmeier, S., Heinemann F., Kappler M., Kraus M., Schrimpf A., Trautwein H.-M. \& Wang, Q. (2009). Potential Output Methods and Problems. Physica-Verlag Heidelberg.

International Monetary Fund. (2015). World Economic Outlook. January. https://www.imf.org/external/pubs/ft/weo/2015/update/01/pdf/ 0115.pdf 
Kirilyuk, I.L. (2013). Models of production function for Russian economy. Computer studies and modeling, 5 (2), $293-312$. Kolemaev, V.A. (2002). Mathematical economy: textbook for universities. 2 ed. Moscow: YUNITI-DANA.

Kurosawa, K. (1975). An aggregate index for the analysis of productivity. Omega, 3 (2), 157-168. doi:10.1016/0305-0483(75)90115-2 Mankiw, N. (1997) Macroeconomics. Inc., NewYork.

McAdam, P., \& Willman A. (2013). Medium Run Redux. Macroeconomic Dynamics, 17(04), 695-727.

Ministry of Economy, Trade and Industry, Japan. (2011). Estimating Potential GDP and Forecasting Deflation. Japan Financial Report, 5 , October. http://www.jcer.or.jp/eng/pdf/kinyuE501.pdf

Shaikh, A. (1974). Laws of Production and Laws of Algebra: The Humbug Production Function. Review of Economics and Statistics, 56 (1), 115-120. doi:10.2307/1927538.

United Nations. (2015). World Economic Situation and Prospects 2015 // http://www.un.org/en/development/desa/policy/wesp/ 